\title{
A REESCRITA DO BILHETE ORIENTADOR PELO LICENCIANDO EM LETRAS: UMA PRÁTICA REFLEXIVO-CRÍTICA NO PROCESSO DE AVALIAR TEXTOS
}

\author{
Francieli Matzenbacher Pinton
}

\begin{abstract}
Resumo: O bilhete orientador é considerado um gênero que possibilita o desenvolvimento de ações e atitudes produtivas ao processo de formação do professor e do aluno (SIGNORINI, 2006). Este trabalho objetiva refletir criticamente sobre a reescrita de bilhetes orientadores produzidos por licenciandos em Letras em um contexto específico de revisão de textos escritos por alunos do ensino fundamental II. Foram analisados 10 bilhetes produzidos e reescritos pelos licenciandos, mediados pelos bilhetes produzidos pelo formador. Os resultados revelam que a primeira versão do bilhete orientador do licenciando enfocou os aspectos microestruturais do texto, apontando-os de forma resolutiva e/ou indicativa. Já a segunda versão focalizou os aspectos macro e microestrurais, apresentando uma revisão mais interativa das dificuldades apresentadas pelos alunos.
\end{abstract}

Palavras-chave: Reescrita. Bilhete Orientador. Formação de Professores.

\begin{abstract}
Guiding notes are considered a genre that allows the development of productive actions and attitudes in the teacher's and student's training process. This paper aims to reflect critically on the rewriting of guiding notes produced by undergraduate students whom are majoring in languages in the specific context of reviewing texts written by high school students. The aspects focused on by the undergraduate students during the textual review were in the macro and micro textual structures. We have analyzed 10 guiding notes produced and rewritten by undergraduate students from the fifth semester, which were mediated by the notes written by their professor. The results show that the first version of the undergraduate students' guiding note focused on textual microstructure, pointing it out in an indicative way or showing it as a solution. The second version focused on both aspects, showing a more interactive review towards the difficulties presented by the producers/students.
\end{abstract}

Keywords: Rewriting. Guiding Notes. Teacher's Training.

\footnotetext{
* Doutora em Letras, Professora Adjunto I da Universidade Federal da Fronteira Sul (UFFS) e Coordenadora do subprojeto PIBID Letras. Contato: francieli.matzembacher@ gmail.com
} 


\section{Considerações iniciais}

A reflexão crítica sobre formação de professores encaminha a discussão para o empoderamento do sujeito professor que busca autonomia no seu fazer docente. Nesse sentido, a formação visa à construção de uma identidade profissional que se fortalece nos saberes da docência e não em uma prática profissional meramente instrumental (NÓVOA, 1995, p. 25). Conforme Schön (1995), esse profissional se caracteriza pela sua capacidade de individualizar, ou seja, por sua capacidade de entender o processo de conhecimento na ação como saber escolar.

Dessa forma, a grande questão é como estabelecer um diálogo produtivo entre os professores formadores e os professores em formação, seja ela inicialou continuada. ParaSignorini(2006), obilheteorientadoréconsiderado um gênero que possibilita o desenvolvimento de ações e atitudes produtivas ao processo de formação do professor e aluno, pois possibilita uma interação afetiva e efetiva. Assim, entendemos que o bilhete pode ser um gênero mediador no processo interlocutivo que se estabelece entre formando e formador.

Em razão disso, este trabalho objetiva refletir criticamente sobre a reescrita de bilhetes orientadores produzidos por licenciandos em Letras em um contexto específico de avaliação de textos escritos por alunos do ensino fundamental II, mediados pelo bilhete do formador. Para tanto, organizamos o artigo em três momentos, além desta introdução: primeiramente contextualizamos a pesquisa, tanto em relação ao aporte teórico quanto metodológico; em seguida, analisamos a escrita e a reescrita dos bilhetes produzidos pelos professores em formação inicial e, por fim; apresentamos nossas considerações finais.

\section{Contextualização da pesquisa}

A recorrente dificuldade encontrada pelos licenciandos para avaliar os textos que os alunos da educação básica produzem foi o que impulsionou esta pesquisa. Diante dessa situação, o questionamento era de que forma poderíamos mediar a ação de avaliar texto, e como isso poderia ser feito em um contexto de formação inicial em que os alunos apresentavam dificuldades não só para avaliar, mas também para produzir seus próprios textos.

Como primeira estratégia, ofertamos uma disciplina optativa que visava: 1) promover a discussão teórica sobre o ensino de produção tex- 
tual; 2) orientar os licenciandos sobre os tipos de correção e, por fim; 3) proporcionar a avaliação de textos de alunos da educação básica. Nesta disciplina, matricularam-se vinte licenciandos oriundos da terceira e quinta fase do curso de Licenciatura em Letras - Português e Espanhol da UFFS.

Durante a discussão teórica sobre o ensino de produção textual, foram apresentadas diferentes perspectivas que podem nortear o ensino de produção textual, em especial, no Brasil. Para Pinton (2012), há quatro perspectivas para ensino: i) a perspectiva da norma que enfoca a prescrição de regras gramaticais, ii) a perspectiva da redação que privilegia não só as regras gramaticais, mas também as textuais; iii) a perspectiva da produção textual que destaca a visão interacional para o ensino e, por fim; iv) perspectiva dos gêneros discursivos/textuais que explicitam e sistematizam as relações entre texto e contexto.

A perspectiva da norma pode ser entendida como aquela em que há predomínio da concepção de língua como sistema de regras, concepção esta impulsionada pelos estudos estruturalistas, cuja ênfase recaía nas análises fonológica, morfológica e sintática da língua. Nesse contexto, a reflexão incidia sobre a teoria tradicional da gramática, apoiada em técnicas da retórica clássica. Conforme Bunzen (2005, p.55), até meados do século XX, "há uma ênfase no ensino de leitura, entendida como prática de decodificação e memorização de textos literários, reservando para o ensino da produção textual um lugar apenas nos níveis mais elevados”.

Já a perspectiva da redação pode ser considerada como o momento em que efetivamente se começa ensinar a escrita de maneira sistemática. Nesse período, a proposta pedagógica recorrente é a da exploração temática, cujas propostas para produção de textos consistiam em solicitar aos alunos uma redação sobre determinado tema, sem que houvesse explicitação da situação sociocomunicativa (cf. BUNZEN, 2006, p. 148). Nesse enfoque, o desenvolvimento da escrita continua sendo visto como resultado da apropriação das normas gramaticais, mas também como resultado de um momento criativo baseado na clássica tipologia: narração, descrição e dissertação.

Em contraponto a esses enfoques, a perspectiva da produção textual aponta para uma diversificação das situações de leitura e escrita em sala de aula, a partir de exemplares variados de texto. Essa nova abordagem surge com a obra fundadora de Geraldi (1984 [2006]), intitulada O texto na sala de aula, que enfatiza um ensino da língua considerando as relações humanas que o perpassam e projetam importantes reflexões acerca do ensino de 
produção textual. Para este autor, para produzir um texto é necessário que: a) se tenha o que dizer; b) se tenha uma razão para se dizer o que se tem a dizer; c) se tenha para quem dizer o que se tem a dizer; d) o locutor se constitua como tal, enquanto sujeito que diz o que diz para quem diz; e) se escolham as estratégias para realizar a, b, c e d. (GERALDI, 1997b, p. 137) .

Nessa mesma linha, a perspectiva dos gêneros discursivos/textuais prevê a adoção dos gêneros como objeto de ensino-aprendizagem, permite e/ou implica a inclusão, para além de aspectos estruturais presentes num texto, de aspectos da ordem da enunciação e do discurso, cuja consciência é fundamental para favorecer os processos de compreensão e produção de textos já que permite: a) incorporação de elementos da ordem do social e do histórico (enredados na sua vinculação com as esferas de comunicação); b) consideração da situação de produção de um dado discurso (quem fala, para quem, lugares sociais dos interlocutores, posicionamentos ideológicos, em que situação, em que momento histórico, em que veículo, em que registro etc.); c) tematização de conteúdos, construções composicionais e estilos verbais (BARBOSA, 2001, p.63-64).

A reflexão sobre as diferentes abordagens para o ensino de produção textual foi produtiva na medida em que os licenciandos identificaram perspectivas correspondentes às práticas de produção de textos experienciadas por eles enquanto alunos da educação básica. Além disso, muitos se mostraram surpresos diante das diferentes abordagens, já que a maioria deles havia experienciado apenas a perspectiva de ensino de produção textual que enfoca as normas gramaticais e textuais. Além disso, estabeleceram relações entre as abordagens para o ensino de produção textual e as diferentes concepções de língua/linguagem subjacentes a elas.

Como a oficina visava à prática de avaliar textos, na atividade subsequente foram apresentadas as diferentes possibilidades para corrigir as produções textuais dos alunos. Primeiramente, foram revisadas as tendências indicativa, resolutiva e classificatória (RUIZ, 2010). Conforme Fuzer (2011), na correção resolutiva, são apontadas soluções para os problemas detectados no texto, com propostas precisas de alterações, em caráter monofônico. Já na correção indicativa, o professor indica, por meio de códigos, os problemas de escrita, essas indicações são feitas, normalmente, à margem do texto produzido. A correção classificatória visa à identificação e à categorização dos problemas, por meio de uma metalinguagem codificada específica. 
Essa proposta de correção é ampliada por Ruiz (2010), a qual aponta para outra possibilidade que é a correção textual-interativa. Segundo a autora, esse tipo de correção é realizado por meio de bilhetes orientadores com o objetivo de estabelecer uma interlocução não codificada com o aluno. Nesse sentido, o bilhete orientador prevê, primeiramente, um leitor interessado no que o aluno tem a dizer; em segundo, um avaliador que analisa as estratégias de dizer empregadas em uma situação comunicativa específica. Assim, o bilhete orienta e não apenas prescreve o que deve ou pode ser feito, estabelecendo uma relação de cumplicidade entre aquele que avalia e aquele que produz o texto.

A reflexão sobre a relação entre as perspectivas para ensino de produção textual e as diferentes formas de avaliar os textos possibilitou aos licenciandos escolher qual seria a forma mais adequada para avaliar os textos. Nesse contexto específico, elegeram a avaliação interativa, realizada por meio de bilhetes orientadores. A justificativa para tal escolha foi a de que coadunavam com a ideia de que uma correção textual-interativa permitiria ao professor não apenas resolver, apontar ou indicar os problemas, mas interagir de forma afetiva durante o processo de produção de textos (RUIZ, 2010; FUZER, 2011). Além disso, os licenciandos afirmaram que esta correção estaria alinhada às perspectivas da produção textual e dos gêneros discursivos/textuais, cujo enfoque foi considerado o mais adequado por eles.

Concluída essa fase, os professores em formação iniciaram o processo de avaliação dos textos. Os textos, que foram objeto de avaliação, foram produzidos por alunos de sétima e oitava séries do ensino fundamental, matriculados em escolas públicas da rede estadual do Rio Grande do Sul. O comando para a produção era que os alunos deveriam se posicionar sobre a importância de leitura na vida do cidadão por meio de um artigo de opinião. Essa proposta foi elaborada e aplicada pelos integrantes do Programa de Bolsas de Iniciação à Docência - Pibid.

Em síntese, os professores em formação inicial leram criticamente os textos teóricos sobre o ensino de produção textual e sobre a avaliação de textos, posicionaram-se sobre a perspectiva a ser adotada e; por fim, tomaram conhecimento do contexto de produção dos textos que seriam avaliados. Após todos esses procedimentos, iniciaram o processo de avaliação dos textos. Na próxima seção, analisamos a avaliação dos textos dos alunos por meio de bilhetes orientadores e a interlocução estabelecida pelo formador por meio do bilhete mediador, assim denominado por nós. 


\section{Avaliação dos bilhetes orientadores escritos pelos licenciandos}

No contexto de formação de professores, o bilhete torna-se um gênero mediador da ação docente na medida em que auxilia o professor formador a avaliar os textos produzidos pelos licenciandos. Além disso, possibilita ao formador analisar de que forma e em que medida os conhecimentos teóricos e metodológicos são mobilizados durante o ato de avaliação pelo professor em formação inicial.

Com base nisso, buscamos analisar os dez bilhetes orientadores escritos pelas duplas de licenciandos e a interlocução do formador realizada por meio do bilhete mediador. Denominamos bilhete mediador, o texto produzido pelo professor formador com o objetivo auxiliar o licenciando em sua atividade de avaliador e também em sua atividade de produtor de texto escrito. Assim, o bilhete mediador pode focalizar tanto aspectos referentes às escolhas/critérios empregados para avaliar o texto do professor em formação, como também, os aspectos referentes à sua produção textual. Neste trabalho, optamos por enfocar a avaliação realizada pelo licenciado e sua estratégia de dizer isso para o aluno.

\subsection{Produção dos bilhetes orientadores}

O trabalho de avaliação iniciou com a leitura dos textos dos alunos da educação básica e com uma breve interlocução entre as duplas sobre as suas primeiras impressões. Após, as duplas produziram a primeira versão do bilhete orientador, sem que houvesse qualquer orientação sobre como deveriam estruturar o bilhete ou sobre quais critérios iriam adotar em sua avaliação. Entretanto, todos licenciandos possuíam clareza do propósito comunicativo do texto que iriam escrever, bem como, para quem este texto estava sendo destinado.

Fuzer (2012), em seu estudo sobre o bilhete orientador como instrumento de interação no processo ensino-aprendizagem de produção textual, identificou a recorrência de quatro movimentos retóricos em bilhetes produzidos por uma professora em formação inicial, sejam eles: M1) reações do leitor ao texto do aluno, M2) elogios à produção, M3) orientações para a reescrita e M4) incentivo à reescrita. Em relação aos bilhetes produzidos pelos licenciandos, percebemos que tais movimentos são preservados, porém, com algumas particularidades. 
O Movimento 1 (reações do leitor ao texto do aluno) ocorre em todos os bilhetes, indicando um comprometimento do avaliador com o dizer do aluno. As escolhas lexicais realizadas para reagir apresentam polaridade positiva, sendo que todos afirmam ter gostado das ideias expressas no texto. Entretanto, observamos que as escolhas indicam diferentes graus de satisfação, como podemos constatar nos exemplos (1 e 2):

\author{
Exemplo 1 \\ Analisando seu texto sobre a leitura, fiquei satisfeita em ver \\ que você soube opinar e argumentar muito bem sobre o tema \\ proposto. \\ Exemplo 2 \\ Querido Y, fico contente em saber o que pensas sobre a lei- \\ tura, pois ela é imprescindível a qualquer ser humano, seja a \\ leitura de periódicos, seja a leitura de textos lúdicos.
}

No Movimento 2 (elogios à produção), observamos a recorrência do qualificador "bom”, indiciando que o avaliador não está preparado e/ou não deseja polarizar sua opinião acerca do texto produzido (Exemplos 3 e 4):

\author{
Exemplo 3 \\ Lendo seu artigo, conclui que está bom, conseguiste desen- \\ volver o tema proposta a partir de boas ideias. \\ Exemplo 4 \\ Seu texto está bom, porque tem muito a nos dizer.
}

Importante sinalizar que o Movimento 2 não aparece na maioria dos bilhetes orientadores, revelando que os licenciandos ainda não se sentem suficientemente empoderados para elogiar o texto do aluno. Tal fato pode nos conduzir à ideia de que a reflexão sobre a o ensino de produção textual na licenciatura não acontece de forma explícita, gerando nos formandos uma insegurança diante da atividade que será desempenhada recorrentemente em toda sua prática docente.

No Movimento 3 (orientações para a reescrita), são fornecidas as orientações para a escrita referentes à macro e a microestrutura do texto ${ }^{1}$.

\footnotetext{
${ }^{1}$ Os aspectos globais remetem a fenômenos linguísticos macroestruturais do texto, típicos do texto como unidade, os de organização textual. Já os aspectos locais dizem respeito aos fenômenos linguísticos tipicamente microestruturais no nível da frase, a saber: os de convenção escrita, os de norma culta, os de léxico e os de estruturação morfossintático-semântica (ANTUNES, 2005; 2010).
} 
Apesar de esta ser a apresentação mais costumeira, nem sempre são contemplados os dois níveis de análise. Além disso, em alguns momentos, os licenciandos não avaliam em momentos distintos tais aspectos, alternando um e outro, conforme vão surgindo esses aspectos nos textos dos alunos.

Essa prática nos dá indícios de que o bilhete foi organizado de acordo com as dificuldades dos alunos, sem que houvesse primeiramente uma avaliação do texto para que posteriormente fosse escrito o bilhete. De acordo com Fuzer (2012), esta pode ser uma das maiores dificuldades enfrentadas pelos professores em formação inicial: a distribuição das informações de modo organizado, a fim de que o aluno possa acompanhar as orientações de forma produtiva.

Por fim, o Movimento 4 (incentivo à reescrita) aparece em todos os bilhetes produzidos, como poder ser verificado nos Exemplos 5, 6 e 7:

\author{
Exemplo 5 \\ Tente reescrever seu texto, levando em conta essas dicas! \\ Exemplo 6 \\ De forma geral suas colocações ficaram muito vagas, mas te- \\ nho certeza de que você pode fazer um planejamento e rees- \\ crever o texto esplendidamente. \\ Exemplo 7 \\ Agora, observando as orientações em sua primeira produção, \\ reescreva este texto fazendo os ajustes necessários. \\ Continue se dedicando e não esqueça 'as palavras têm poder'.
}

A recorrência deste momento comprova a perspectiva assumida de texto como processo, ou seja, todos os licenciandos entendem que a produção exige planejamento, produção e reescrita. Como movimento subsequente, apresento de que forma os bilhetes orientadores foram mediados pelo professor formador.

\title{
3.2 Reescrita dos bilhetes orientadores
}

A mediação do ato de avaliar texto, neste contexto de formação, busca promover a reflexão sobre os saberes que são mobilizados pelos licenciandos, incentivando e intervindo nesse fazer docente de forma efetiva. Nesse sentido, o bilhete mediador busca responder criticamente ao bilhete orientador, estabelecendo um diálogo produtivo, que valoriza a avaliação realizada e, ao mesmo tempo, sinaliza o 
que pode ser melhorado e/ou aperfeiçoado. Esse movimento dialógico pode ser visualizado no Bilhete orientador 1 e no Bilhete mediador 1:

\section{Bilhete 1}

Aluno $X$, seu texto está bom, porque tem muito a nos dizer. Porém, suas ideias estão um pouco desorganizadas no texto. Para melhorá-lo sugiro algumas alterações. Tente criar um título mais específico e refaça o primeiro parágrafo selecionando verbos mais adequados, que não deixem a ideia tão vaga. Além disso observe as sinalizações feitas no texto com relação à ortografia e à repetição de informações. Procure utilizar em seu texto apenas uma pessoa verbal (não utilize em alguns momentos "nós" e em outros "as pessoas"). No último parágrafo comente sua citação, para melhor concluir seu texto. Tente também fazer uma conexão entre os parágrafos e reveja suas justificativas após suas afirmações. Enfim, acredito que você tenha capacidades de reescrever e melhorar seu texto. Pense nisso! Bilhete mediador 1

Caras Licenciandas!

O bilhete orientador produzido por vocês tematiza os aspectos global e local do texto do aluno. Os aspectos globais remetem a fenômenos linguísticos macroestruturais, típicos do texto como unidade: são os de organização textual. Já os aspectos locais dizem respeito aos fenômenos linguísticos tipicamente microestruturais no nível da frase, a saber: os de convenção escrita, os de norma culta, os de léxico e os de estruturação morfossintático-semântica. Embora ambos os aspectos sejam referenciados no bilhete, observei uma alternância entre os aspectos locais e globais que, de certa forma, prejudica o entendimento das sugestões e/ou adequações propostas por vocês. Diante disso, sugiro que um novo encaminhamento, que sinalize, em separado, cada um desses aspectos. Gostei muito da estratégia empregada para dizer ao aluno o que pode ser melhorado. Além disso, as sugestões apresentadas são precisas, fornecendo pistas de como ele pode aperfeiçoar o aspecto por vocês sinalizado. Como sugestão, que tal incluir alguns questionamentos que permitam refletir sobre outras formas de dizer. Bom trabalho! 
Nessa perspectiva, o texto é entendido como um processo e a formação entendida como uma ação reflexiva da prática. Em razão disso, bilhete mediador tem como propósito proporcionar ao formando a autoanálise da avaliação realizada, permitindo que ele conceba sua formação não como algo que se conclui com a graduação, mas como algo permanente que se (re) constrói, circularmente.

Sendo assim, como resposta à mediação os licenciandos escreveram a segunda versão do Bilhete 1 :

\section{Caro X!}

Seu texto está bom, porque tem muito a nos dizer. Porém, suas ideias estão um pouco desorganizadas no texto. Para melhorá-lo sugiro algumas alterações.

Refaça o primeiro parágrafo selecionando verbos mais adequados, que não deixem a ideia tão vaga. Além disso, tente também fazer uma conexão entre os parágrafos e reveja suas justificativas após suas afirmações. Ainda em relação os parágrafos, você afirma, no terceiro parágrafo, que só o livro que escolhemos pode nos levar para outro mundo. Mas será que só os livros do nosso interesse que nos levam a isso? E os outros livros? Já no quinto parágrafo você afirma que a leitura é muito importante nos dias de hoje. Mas só nos dias de hoje ou será que ela sempre foi importante?

Em relação ao último parágrafo, comente sua citação para melhor concluir seu texto.

Além disso, observe as sinalizações feitas no texto com relação à ortografia e à repetição de informações. Procure, também, utilizar em seu texto apenas uma pessoa verbal (não utilize em alguns momentos "nós" e em outros "as pessoas"). Após ter feito todas essas modificações, releia o texto e procure formular um título mais específico e chamativo.

Enfim, acredito que você tenha capacidades de reescrever e melhorar seu texto. Pense nisso!

Ao compararmos a primeira versão do bilhete orientador e a segunda versão, mediada pelo bilhete do formador, percebemos que há uma reprodução do modelo de chamamento empregado no bilhete mediador. Tal atitude pode significar que as avaliadoras buscam uma estrutura textual similar, entendendo que o bilhete do formador em certa medida pode ser considerado como um modelo. Nessa mesma perspectiva, observamos que há uma anuência às sugestões do professor formador, ou seja, o licenciando 
incorpora, em seus bilhetes, as orientações prescritas.

Embora haja anuência, a reflexão limita-se às alterações propostas pelo formador, sem acréscimos. Mesmo não havendo acréscimos, percebemos que é justamente nesta inserção de questionamentos que o bilhete efetiva a interação como nestes exemplos: "Mas será que só os livros do nosso interesse que nos levam a isso? E os outros livros? Já no quinto parágrafo você afirma que a leitura é muito importante nos dias de hoje. Mas só nos dias de hoje ou será que ela sempre foi importante?", demonstrando o esforço do professor em formação para fazer com que o texto produzido avance em termos de conteúdo temático.

Além disso, há uma sinalização de que no texto foi realizada uma correção indicativa e resolutiva. Tal sinalização indica que os formandos sentem a necessidade de fazer uso de mais de um tipo de correção, remetendo à crença de que para os aspectos formais a indicação e/ou resolução é eficaz.

No Bilhete 2, a primeira versão demonstra que os professores em formação inicial enfrentam dificuldades para mobilizar os saberes necessários para avaliar o texto do aluno. Dessa forma, optam por uma orientação mais vaga, sem enfocar o que realmente precisa ser modificado:

Cara XY, seu texto manteve-se fiel ao tema proposto, leitura. Porém a argumentação não foi convincente e coesa, talvez pelas frases que necessitavam explicações mais completas, a fim de que o leitor pudesse compreender seu posicionamento frente à importância que o ato de ler e pudesse formar consciência de acordo com os seus argumentos, visto que o gênero produzido, artigo de opinião, tem como objetivo defender a ideia do escritor e persuadir o leitor.

Agora, observando as orientações em sua primeira produção, reescreva este texto, fazendo os ajustes necessários.

Continue se dedicando e não esqueça "as palavras têm poder".

O bilhete mediador procura desafiar as professoras a rever sua avaliação:

Caras licenciandas W e Z!

O bilhete orientador produzido por vocês tematiza o aspecto global do texto do aluno. Como vocês sabem, os aspectos globais remetem a fenômenos linguísticos macroestruturais, típicos do texto como unidade. Portanto, referem-se à orga- 
nização textual. Apesar dessa focalização, as sinalizações não são precisas, pois não apontam caminhos nem questionamentos que possam contribuir para o aperfeiçoamento do texto revisado. Mais que apontar os problemas é necessário dar pistas de como o texto pode ser reconstruído. Sugiro que explicitem os aspectos globais e locais que precisam ser melhorados no texto do aluno e deixem claras as orientações que ele pode/ deve seguir para o momento da reescritura.

Bom trabalho!!!

Podemos notar que houve uma significativa modificação na produção do bilhete, já que na segunda versão há uma ampliação e um acréscimo de orientações fornecidas na primeira versão:

Cara XY, seu texto manteve-se fiel ao tema proposto, leitura. Porém a argumentação não foi convincente, talvez pelas frases que necessitam explicações mais completas, como, por exemplo, na primeira frase de seu texto, em que você apresenta verbos sem complemento; lá você diz "nos ensina", mas não explica o que nos ensina; isso se repete no momento em que diz "A leitura faz com que todos nós tornamos iguais porque nos esclarece coisas que não temos certeza", mas o que são essas coisas que não temos certeza? (Ampliação)

A citação usada foi de ótima escolha, entretanto uma citação não deve apenas ser "jogada" no texto. Ela deve aparecer e ser comentada, apresentando a relação entre ela e o que você escreveu. (Acréscimo)

Quanto às palavras empregadas, acreditamos que deveria ser utilizada a linguagem formal, pois é uma das características do gênero artigo de opinião. A escolha das palavras é muito importante. Na parte do texto em que você diz que "até pra ser varredor de rua as pessoas exigem que no mínimo a pessoa tenha a oitava série completa", ao usar o "até" demonstra certo preconceito, pois desvaloriza a profissão de gari. Na mesma frase acontece a repetição da palavra "pessoa" o que não pode acontecer, visto que o vocabulário é muito grande e inúmeras outras palavras poderiam ter sido utilizadas naquela frase. (...)

Diferentemente do outro, este bilhete não reproduz o modelo de chamamento empregado no bilhete mediador, dando indícios de que os licenciandos não se preocuparam em comparar as estruturas textuais empregadas pelo formador. Entretanto, constatamos que houve um movimento no sentido de que os licenciandos não só aceitaram as sugestões, como 
também acrescentaram sugestões e orientações para o aluno.

Outro ponto a ser destacado é a presença de um discurso que prioriza a didatização das orientações e/ou sugestões dadas ao aluno. Dessa forma, percebemos que os licenciandos se esforçam para fornecer as instruções necessárias, na medida em que buscam justificar o porquê de tais orientações.

Enfim, podemos afirmar que a circularidade proposta nesta atividade formativa corrobora para que os formandos avancem em sua prática de avaliar textos, ao mesmo tempo em que proporciona aos formadores a possibilidade de (re) construir seu papel de formador. Tal circularidade se materializa no momento em que o professor em formação inicial avalia o texto do aluno da educação básica e o professor formador avalia o bilhete orientador por meio dos conhecimentos teóricos e metodológicos mobilizados neste processo, conforme a Fig. 1 .

Figura 1 - Circularidade discursiva e textual na atividade formativa

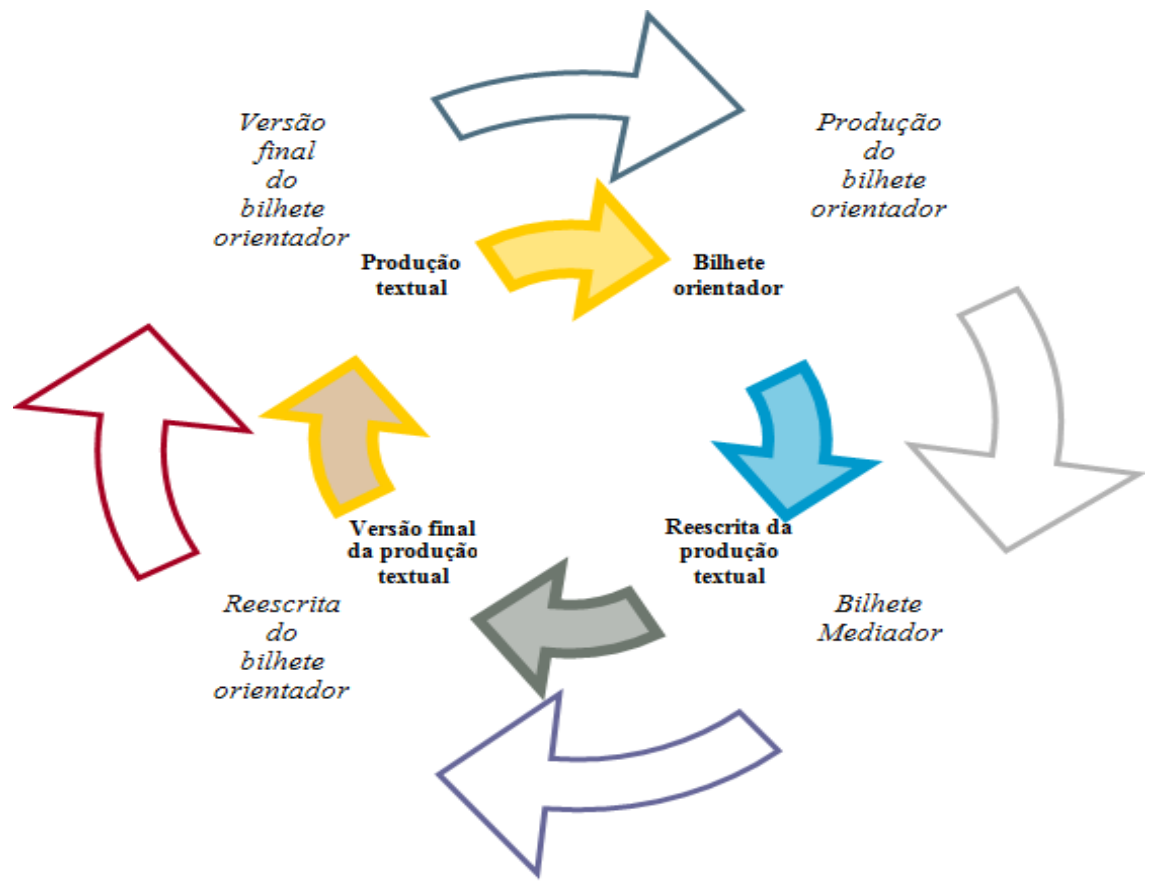


Portanto, a intervenção por meio de bilhetes promove avanços significativos, tanto para o produtor de textos em fase inicial, como para o professor em formação inicial. Tal avanço só acontece porque há um leitor interessado no texto que avalia, e um avaliador que se esforça para que as suas sugestões/orientações sejam úteis e permitam a (re)construção de seu texto de modo a atingir seus objetivos.

\section{Considerações finais}

Para os professores em formação inicial, o ato de avaliar textos é bastante complexo, visto que precisam mobilizar conhecimentos teóricos e metodológicos que estão sendo construídos na graduação. Nesse sentido, o bilhete orientador e o bilhete mediador podem ser considerados gêneros que possibilitam um avanço significativo dos materiais escritos. Entretanto, não só avanço do material escrito deve ser levado em conta, mas também o avanço do saber docente, que a cada mediação pode ser (re)construído de forma mais produtiva e afetiva.

Além disso, há de se considerar que a interlocução entre formador e licenciando permite analisar de que forma são mobilizados os conhecimentos teóricos e pedagógicos para avaliar os textos, contribuindo para a (re) formulação dos currículos dos cursos de licenciatura em Letras. 


\section{Referências}

ANTUNES, I. Lutar com palavras: coesão e coerência. São Paulo: Parábola Editorial, 2005.

. Análise de textos: fundamentos e práticas. São Paulo: Parábola Editorial, 2010.

BARBOSA, J. P. Trabalhando com os gêneros do discurso: uma perspectiva enunciativa para o ensino de Língua Portuguesa. 2001. 233f. PUC - SP. Tese (Doutorado em Linguística Aplicada ao Ensino de Línguas), Programa de Pós-Graduação em Linguística Aplicada e em Estudos da Linguagem, Pontifícia Universidade Católica de São Paulo, São Paulo.

BUNZEN, C. Da era da composição à era dos gêneros: o ensino de produção de texto no ensino médio. In: BUNZEN, C. MENDONÇA, M. (Org.). Português no ensino médio e formação do professor. São Paulo: Parábola Editorial, 2006. p.139-161.

. O livro didático de língua portuguesa: um gênero do discurso. 2005. 168f. Dissertação (Mestrado em Lingüística Aplicada). - Programa de Pós-Graduação em Linguística Aplicada, Universidade Estadual de Campinas, Campinas.

FUZER, C. Leitura e avaliação de textos. Santa Maria: Universidade Federal de Santa Maria, Departamento de Letras Vernáculas, Curso de Letras, 2011.

. Bilhete orientador como instrumento de interação no processo ensino-aprendizagem de produção textual. Letras. Santa Maria, v.22, n.44, p. 213-245, 2012.

GERALDI, J. W. Da redação à produção de textos. In: GERALDI, JW.; CITELLI, B. (Org.). Aprender e ensinar com textos de alunos. São Paulo: Cortez, 1997a. v.1. 
Portos de passagem. 4.ed. São Paulo: Martins Fontes, 1997b.

NÓVOA, A. A formação de professores e profissão docente. In (org.). Os professores e sua formação. 2.ed. Lisboa: Publicações $\overline{\text { Dom Qui- }}$ xote, 1995. p. 15-34.

PINTON, F. M. Análise crítica de gênero de reportagens didáticas sobre o ensino de produção textual na revista Nova Escola (2006-2010). 2012. 195f. Tese (Doutorado em Letras) - Programa de Pós-Graduação em Letras, Universidade Federal de Santa Maria, Santa Maria.

RUIZ, E. D. Como corrigir redações na escola: uma proposta textual-interativa. São Paulo: Contexto, 2010.

SCHÖN, D. Formar professores como profissionais reflexivos. In NÓVOA, A. (org). Os professores e sua formação. 2.ed. Lisboa: Publicações Dom Quixote, 1995. p. 77-91.

SIGNORINI, I. Gêneros catalisadores: letramento e formação do professor. São Paulo: Parábola Editorial, 2006.

Recebido em: outubro de 2012.

Aprovado em: março de 2013. 